
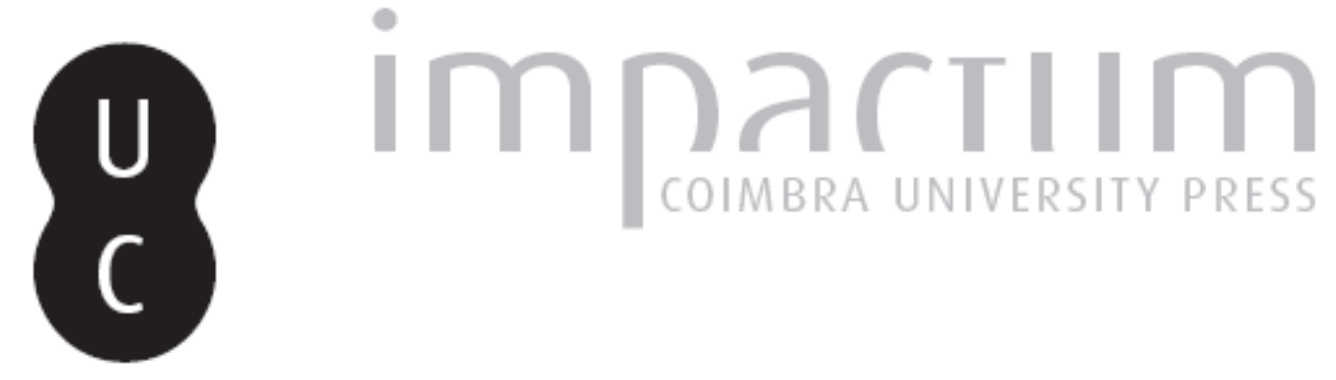

\title{
Avaliação do risco de incêndio em centros urbanos antigos. Parte II: aplicação informática sobre o método de Arica
}

Autor(es): $\quad$ Figueira, Rui; Coelho, António Leça; Rodrigues, João Paulo C.

Publicado por: Associação Portuguesa de Riscos, Prevenção e Segurança

URL

persistente:

URI:http://hdl.handle.net/10316.2/35945

DOI:

DOI:http://dx.doi.org/10.14195/1647-7723_19_14

Accessed : $\quad$ 26-Apr-2023 13:21:12

A navegação consulta e descarregamento dos títulos inseridos nas Bibliotecas Digitais UC Digitalis, UC Pombalina e UC Impactum, pressupõem a aceitação plena e sem reservas dos Termos e Condições de Uso destas Bibliotecas Digitais, disponíveis em https://digitalis.uc.pt/pt-pt/termos.

Conforme exposto nos referidos Termos e Condições de Uso, o descarregamento de títulos de acesso restrito requer uma licença válida de autorização devendo o utilizador aceder ao(s) documento(s) a partir de um endereço de IP da instituição detentora da supramencionada licença.

Ao utilizador é apenas permitido o descarregamento para uso pessoal, pelo que o emprego do(s) título(s) descarregado(s) para outro fim, designadamente comercial, carece de autorização do respetivo autor ou editor da obra.

Na medida em que todas as obras da UC Digitalis se encontram protegidas pelo Código do Direito de Autor e Direitos Conexos e demais legislação aplicável, toda a cópia, parcial ou total, deste documento, nos casos em que é legalmente admitida, deverá conter ou fazer-se acompanhar por este aviso.

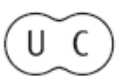




\section{territorium}

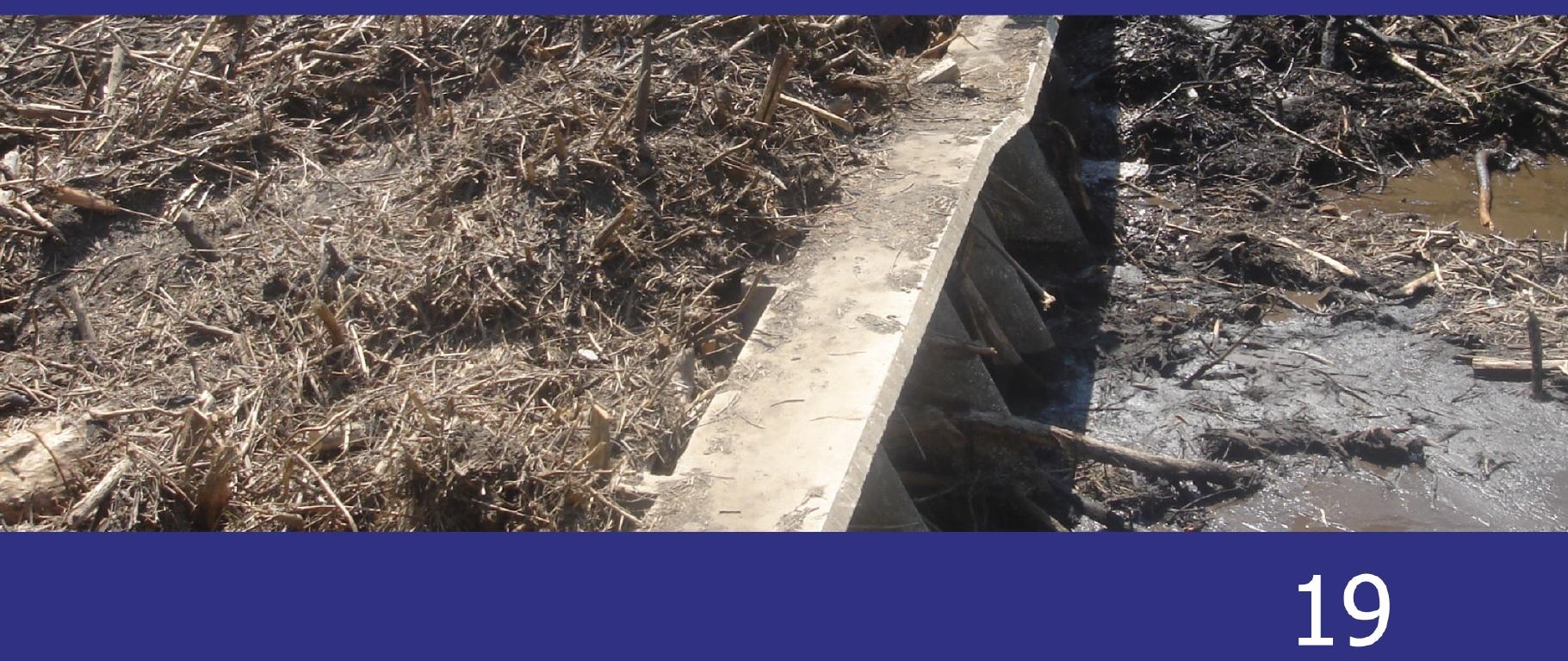

\section{Reequacionar o Conhecimento dos Riscos e das Catástrofes}

Revista da Associação Portuguesa de Riscos, Prevenção e Segurança 


\section{AVALIAÇÃO DO RISCO DE INCÊNDIO EM CENTROS URBANOS ANTIGOS. PARTE II - APLICAÇÃO INFORMÁTICA SOBRE O MÉTODO DE ARICA*}

Rui Figueira

Serviço de Protecção Civil da Câmara Municipal do Funchal ra.figueira@gmail.com

António Leça Coelho

Laboratório Nacional de Engenharia Civil alcoelho@lnec.pt

João Paulo C. Rodrigues

Faculdade de Ciências e Tecnologia da Universidade de Coimbra jpaulocr@dec.uc.pt

\section{RESUMO}

Nesta segunda parte do artigo "Avaliação do risco de incêndio em centros urbanos antigos” faz-se a apresentação dum programa de computador desenvolvido para a aplicação do método ARICA. Este programa permite a aplicação do método duma forma simples e sistematizada traduzindo-se com isso numa maior inteligibilidade das soluções a testar e numa economia de tempo

Palavras chave: Risco de incêndio, centro urbano antigo, programa.

\section{RESUMEN}

Evaluación del riesgo de incendios en centros urbanos antiguos. Parte II - Aplicación informática del método de ARICA. En esta parte de "Evaluación del riesgo de incendios en centros urbanos antiguos" se hace la presentación de una aplicación informática del método ARICA que se hay desarrollado recientemente. Este software permite la aplicación del método de una manera más sencilla y sistemática con un ahorro de tiempo y una mayor facilidad de comprensión de los casos de estudio.

Palabras clave: Riesgo de incendio, centro urbano antiguo, programa.

\section{RÉSUMÉ}

Evaluation de risque d'incendie dans les centres urbains historiques. II Part - Application informatique de la méthode ARICA. Dans cette partie de l'article “Évaluation de risque d'incendie dans les centres urbains historiques" est faite la présentation d'une application informatique de la méthode ARICA récemment développé. Ce logiciel permet l'application de la méthode d'une forme claire et systématique qui se traduit par une plus grande intelligibilité des solutions d'essai et un gain de temps. Mots-clés: Risque d'incendie, centre urbain historique, programme.

\section{ABSTRACT}

Fire risk assessment in old urban areas. Part II - Software of the method ARICA. In this part of the paper "Fire risk assessment of old urban centres" a computer program of the method ARICA recently developed is presented. This software allows the application of the method in a simpler and systematic way allowing this a better understanding of the solutions and a notorious save of time.

Key words: Fire risk, old urban centre, software.

* O texto deste artigo corresponde à comunicação apresentada ao II Congresso Internacional de Riscos e VI Encontro Nacional, tendo sido submetido para revisão em 08-06-2010, tendo sido aceite para publicação em 23-09-2010. Este artigo é parte integrante da Revista Territorium, n. ${ }^{\circ} 19,2012,{ }^{\circ}$ RIscos, ISBN: 0872- 8941 


\section{Introdução}

O método de análise de risco mais utilizado a nível internacional é o de Gretener. Este método desenvolvido pelo engenheiro suíço Max Gretener tem sido aplicado de forma indistinta a qualquer tipo de edificação incluindo as zonas urbanas antigas. 0 método apresenta várias limitações para alguns tipos de aplicações como, por exemplo, para os Centros Urbanos Antigos. Assim, nesta base desenvolveu-se o método de ARICA (Analise de Risco de Incêndio em Centros Antigos) (Fernandes, 2006) que entra em conta com um maior conjunto de parâmetros com influência nas referidas zonas.

Nesta parte do artigo, sobre o risco de incêndio em centros urbanos antigos, faz-se a apresentação e descrição dum programa de computador desenvolvido para aplicar o método de ARICA duma forma mais simplificada e sistemática. Este programa permite evitar a consulta de manuais, valores tabelados, garantindo assim uma utilização mais cómoda do método com uma grande economia de tempo (FIGUEIRA, 2008).

Um dos objectivos deste software foi que a sua utilização requeresse uma aprendizagem relativamente curta, contribuindo para isso que este fosse de intuição rápida, que possuísse uma apresentação gráfica e uso comum a ferramentas informáticas já do conhecimento geral dos futuros utilizadores. Dessa forma poder-se-ia garantir uma aprendizagem simples, célere e cómoda, embora não seja posta de parte a necessidade de conhecimento do método de análise.

Este software foi criado em linguagem C\#, sendo todo o código desenvolvido numa plataforma integrada de desenvolvimento do MS Visual Studio 2008 Express Edition.

\section{O software ARICA}

\section{Descrição da interface do software}

Ao iniciar o software, este abre a seguinte janela, da qual constam os menus "Ficheiro" e "Ajuda".

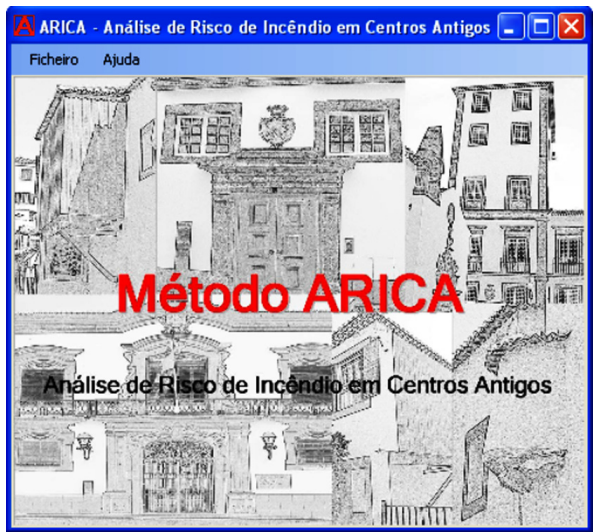

Fig. 1 - Janela inicial do ARICA (Fonte: software ARICA).
As figuras seguintes (fig. 2 e 3 ) demonstram as opções existentes ao clicar em "Ficheiro", nomeadamente as opções activas, "Novo", "Abrir" e "Sair". Ao clicar na "Ajuda", consta uma ligação com o mesmo nome e "Acerca do ARICA".

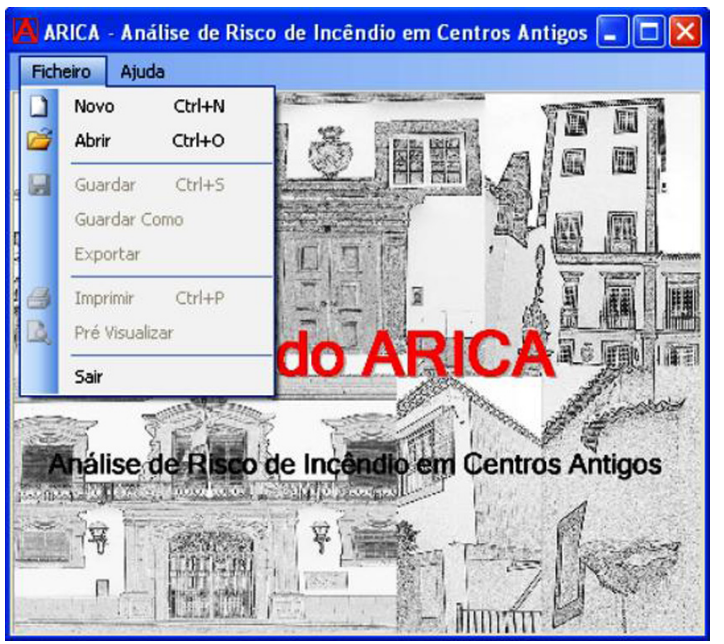

Fig. 2 - Composição do Menu Ficheiro ao iniciar o programa (Fonte: software ARICA).

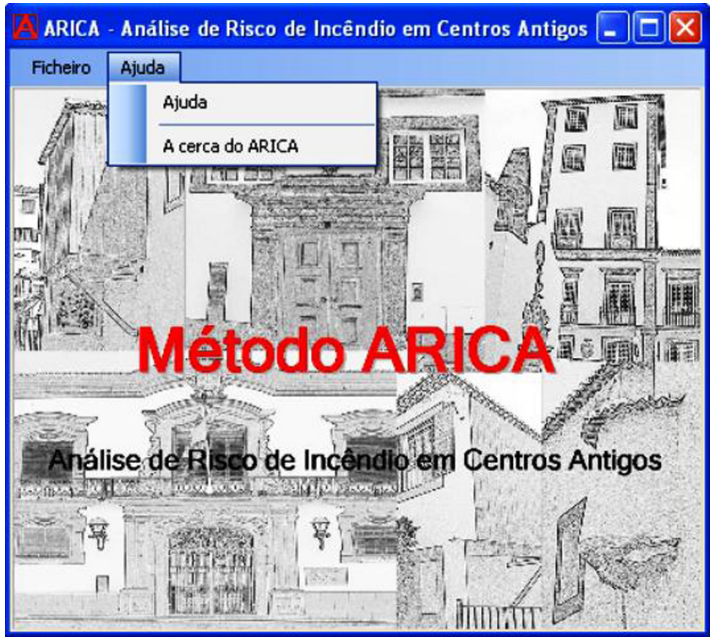

Fig. 3 - Composição do Menu Ajuda (Fonte: software ARICA).

Ao seleccionar a opção "Novo", abrir-se-á a janela seguinte (fig. 4), denominada "Cálculo Risco Incêndio Método ARICA". Esta janela, interactiva, contem toda a informação relevante acerca da identificação do edifício em análise "Nome”, “Localização" e “Tipo(s) de Utilização, que constará do relatório obtido no final do cálculo do risco de incêndio. Os restantes ícones correspondem aos diversos factores globais, onde se pode iniciar o seu cálculo.

Da restante janela constam os valores obtidos para os factores de risco FRI e FRR e o Risco de Incêndio (ver parte I do artigo), sendo que estes valores são obtidos automaticamente quando os quatro factores globais tiverem sido calculados. 


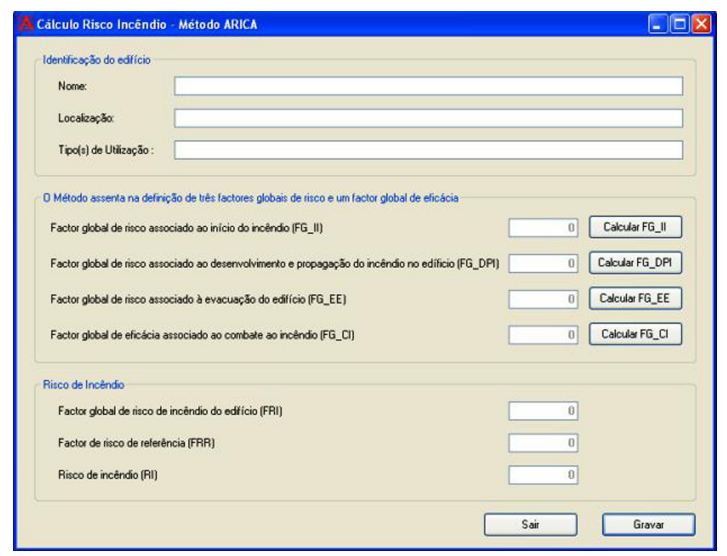

Fig. 4 - Janela resumo do Método (Fonte: software ARICA).

\section{Os diferentes tipos de janelas e formas de cálculo}

Face ao número de janelas existentes, não é viável a apresentação de todas, pelo que se reuniu todas as janelas distintas existentes no software.

A janela seguinte (fig. 5) apresenta a listagem dos vários factores parciais que constituem o FGII, factor global de risco associado ao início de incêndio nomeadamente o FEC, FIEL, FIG, FNCl. Os valores 0 (zero) significam que ainda não foi calculado ou seleccionada a opção correspondente do respectivo factor parcial.

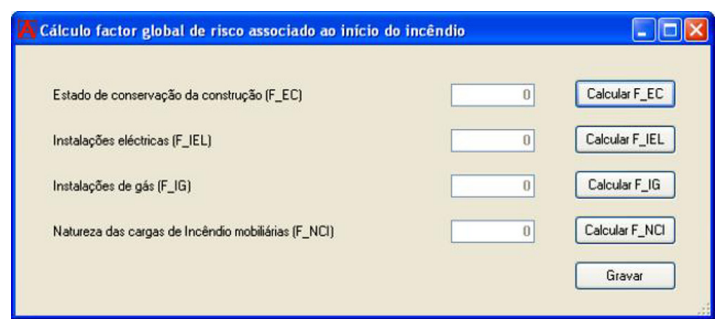

Fig. 5 - Janela de cálculo dos factores parciais do FGII (Fonte: software ARICA).

O factor parcial das instalações eléctricas, FIEL (fig. 6), é composto por várias opções, embora só seja possível seleccionar uma das existentes. Para estes casos existem os RadioButtons (é um botão que só permite a selecção de um desses por janela (Form) ou conjunto de elementos agrupados (GroupBox)), onde só é possível seleccionar uma única opção.

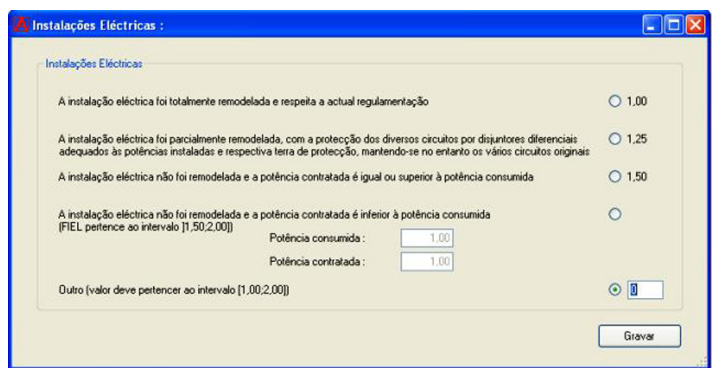

Fig. 6 - Janela de cálculo do FIEL (Fonte: software ARICA).
Na fig. 7 é possível ver uma opção seleccionada cuja função é activar outros dois campos, até aí inacessíveis à introdução de qualquer dado.

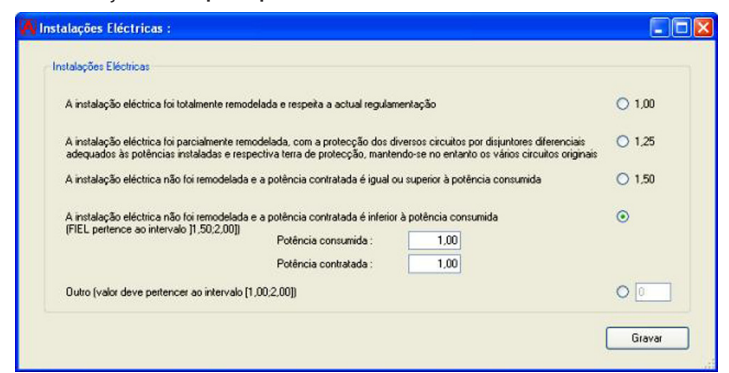

Fig. 7 - Exemplo de campos acessíveis após selecção da respectiva opção (Fonte: software ARICA).

No caso das instalações de gás, devido à possibilidade de existirem vários tipos de rede num edificado, a opção passa a ser a dos CheckBox (botão que permite a selecção de várias opções por janela (Form) e/ou conjunto de elementos agrupados (GroupBox) - fig. 8).

\begin{tabular}{|c|c|}
\hline Instalaçōes de Gás & $-\square \times$ \\
\hline Edificio com abastecimento de gás canalizado (gás natural ou gás de cidade) & $\square 1,0$ \\
\hline $\begin{array}{l}\text { Edifício com abastecimento através de reservatórios de gás (propano ou butano) } \\
\text { com a devida manutençãá periódica }\end{array}$ & $\square 1.1$ \\
\hline $\begin{array}{l}\text { Edifício com utilização de garafas de gás (propano ou butano) armazenadas ou } \\
\text { instaladas no exterior do edificio ou em locais muito bem ventiados }\end{array}$ & $\square 1.2$ \\
\hline $\begin{array}{l}\text { Edifício com utitização de garrafas de gás (propano ou butano) amazenadas ou } \\
\text { instaladas no interior do edifício em local ventilado }\end{array}$ & 甲 1.5 \\
\hline $\begin{array}{l}\text { Edifício com utilização de garrafas de gás (propano ou butano) armazenadas ou } \\
\text { instaladas no interior do edííicio em local nẫo ventilado }\end{array}$ & च 1.8 \\
\hline Outro (valor deve pertencer ao intervalo $[1,00 ; 1,80]]$ & 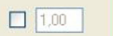 \\
\hline 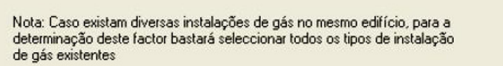 & Gravar \\
\hline
\end{tabular}

Fig. 8 - Janela de cálculo do FIG (Fonte: software ARICA).

Sempre que é efectuada alguma alteração das opções anteriormente gravadas, ao clicar no Fechar (fig. 9) será devolvido um aviso, garantindo-se que os valores não sejam alterados inadvertidamente. Ao clicar "Gravar", automaticamente as alterações são gravadas e encerrada a janela.

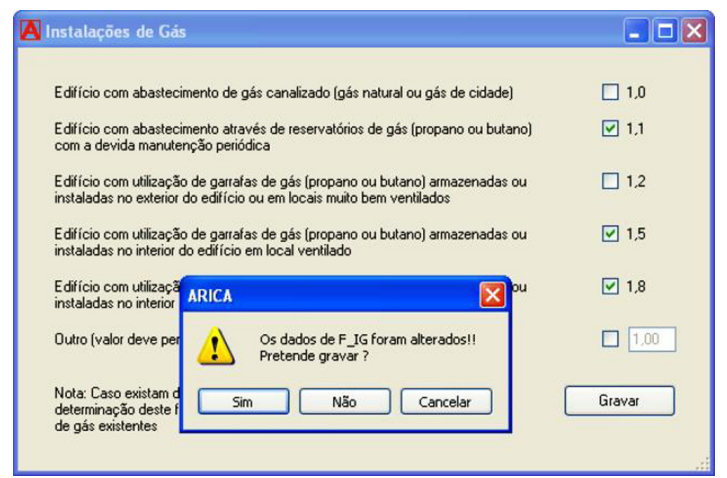

Fig. 9 - Erro de fecho após alteração de valores (Fonte: software ARICA).

Outro possível erro, seria a introdução de um valor distinto, num dado campo, do permitido pelo intervalo definido (fig. 10), que neste caso o valor deverá estar 
enquadrado entre 1,00 e 1,20. Visto a opção escolhida tinha sido o "3", foi devolvido um aviso com o erro realizado.

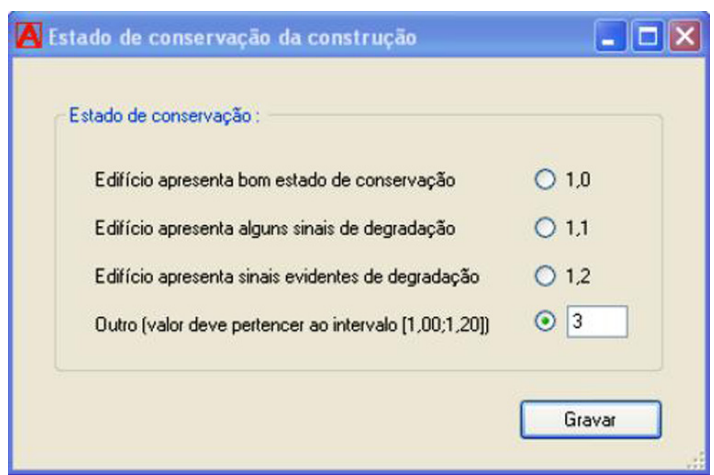

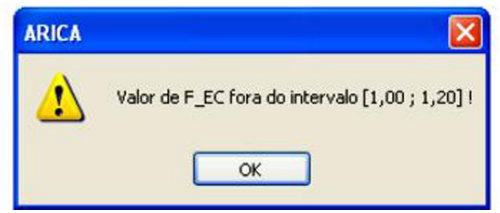

Fig. 10 - Erro por introdução de valor distinto do intervalo definido (Fonte: software ARICA).

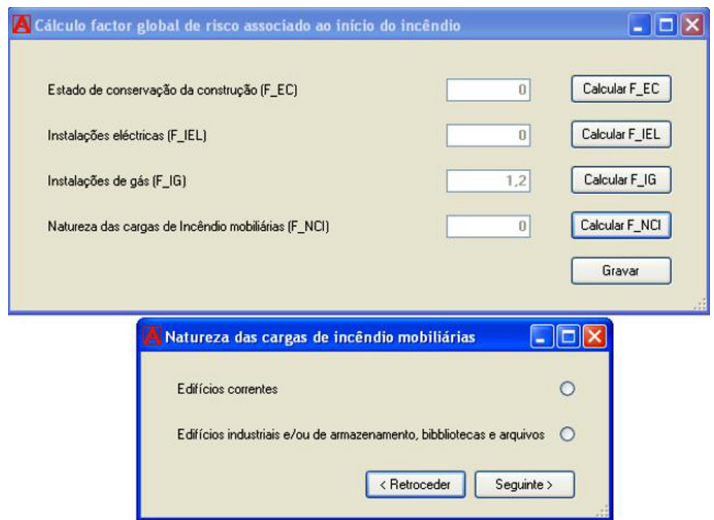

Fig. 11 - Exemplo de cálculo de factor parcial (Fonte: software ARICA).

A forma de obtenção do factor parcial relativo à natureza das cargas de incêndio mobiliárias é distinta dos apresentados anteriormente, existindo duas hipóteses distintas de cálculo (fig. 11), no qual podem ser "edifícios industriais e/ou de armazenamento, bibliotecas e arquivos" ou, quando não sendo nenhum destes casos, a opção a escolher deverá ser a dos “edifícios correntes”. No caso da opção recair nos edifícios correntes, abre-se uma janela em que o cálculo é feito através de um DatagridView (é uma tabela que permite a introdução de vários tipos de dados (texto, números, imagens, links, etc.) apresentando esses dados de forma estruturada, uma espécie de Folha de Cálculo (fig. 12). Na mesma figura é possível verificar-se que a opção de escolha do parâmetro $\mathrm{Ci}$ (cujos valores são tabelados) é efectuada através de ListBox (permite ao utilizador escolher uma de entre várias opções prédefinidas). Neste software limitou-se o número de linhas nos DatagridView a 100 entradas.

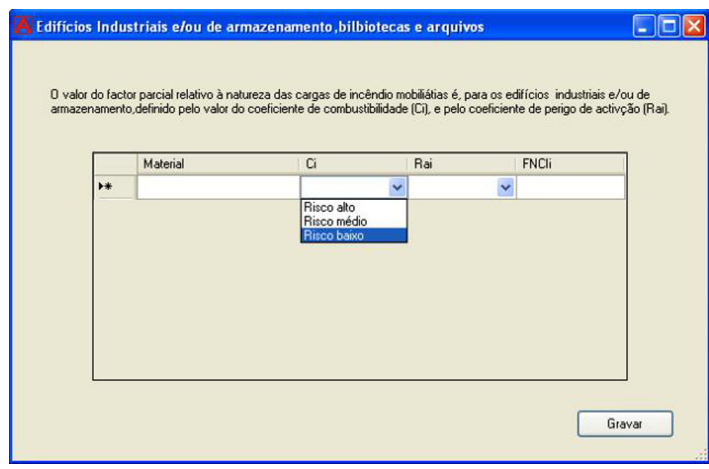

Fig. 12 - Exemplo de cálculo de um factor parcial utilizando DatagridView com ListBox (Fonte: software ARICA).

A Figura 13 é composta por um DatagridView onde igualmente se verificam alguns valores tabeladas duma dada coluna. Neste caso, definiu-se que o preenchimento dos dados no DatagridView só é permitido quando a respectiva opção for seleccionada. Na coluna "Valor Parcial" surge o valor de cálculo relativo ao hidrante exterior identificado como " 1 ". Nestes casos a primeira coluna corresponde à identificação do objecto a ser tratado, neste caso foi atribuída uma numeração aos vários hidrantes, embora a opção do preenchimento dessa coluna possa ser distinta, consoante a descrição escolhida pelo utilizador.

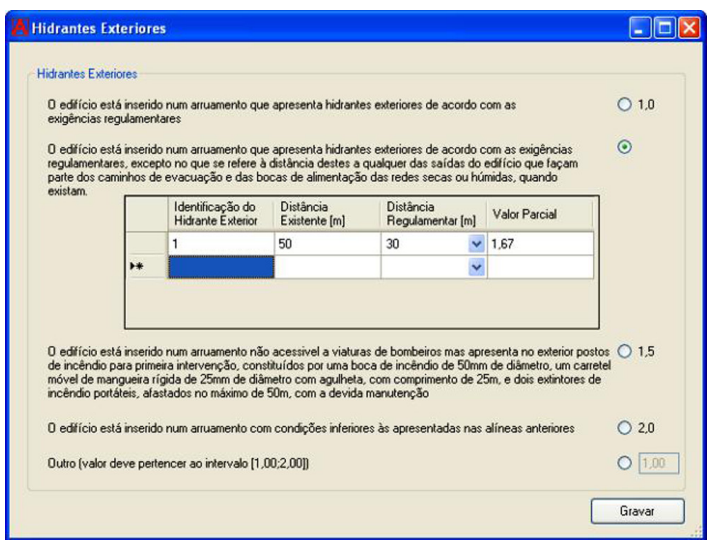

Fig. 13 - Janela de cálculo com valores tabelados e DatagridView (Fonte: software ARICA).

O exemplo ilustrado na fig. 14 é idêntico ao anterior, com a nuance de dois RadioButton activarem campos inacessíveis (neste caso dois, embora possam ser mais) à introdução de dados. Relembra-se que neste caso os dados são dois campos de texto (TextBox) embora possa ser, igualmente, um DatagridView.

No caso seguinte (fig. 15), o afastamento regulamentar entre vãos é fixado com o valor $1,10 \mathrm{~m}$, pelo que o utilizador só necessita de introduzir o valor correspondente à distância real existente, sendo que o programa efectua o cálculo automaticamente. 


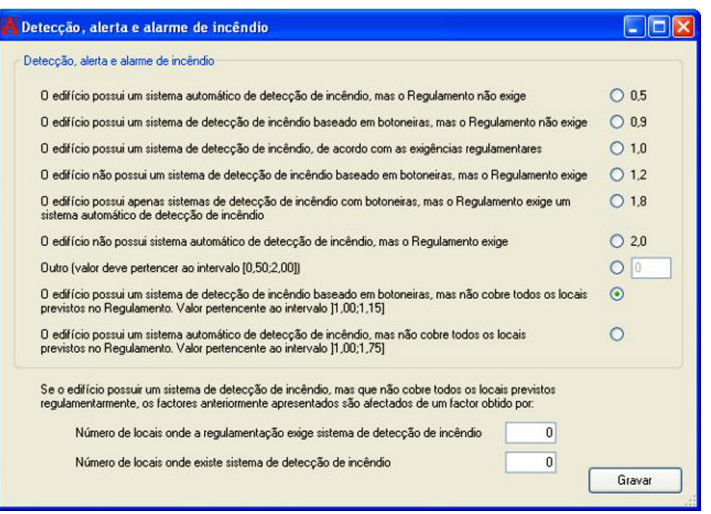

Fig. 14 - Exemplo de mais dum RadioButton a activar campos inacessíveis à introdução de dados (Fonte: ARICA).

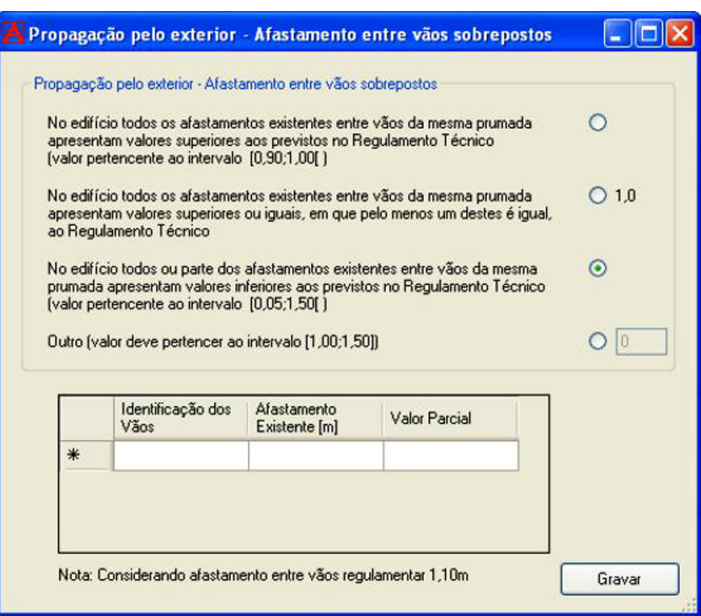

Fig. 15 - Exemplo de janela com DatagridView com um valor fixo (Fonte: software ARICA).

Como alguns dos factores parciais estarão associados a mais que um factor global, quando um desses valores é gravado num determinado factor global, automaticamente é alterado e guardado nos restantes factores globais (fig. 16, 17 e 18).

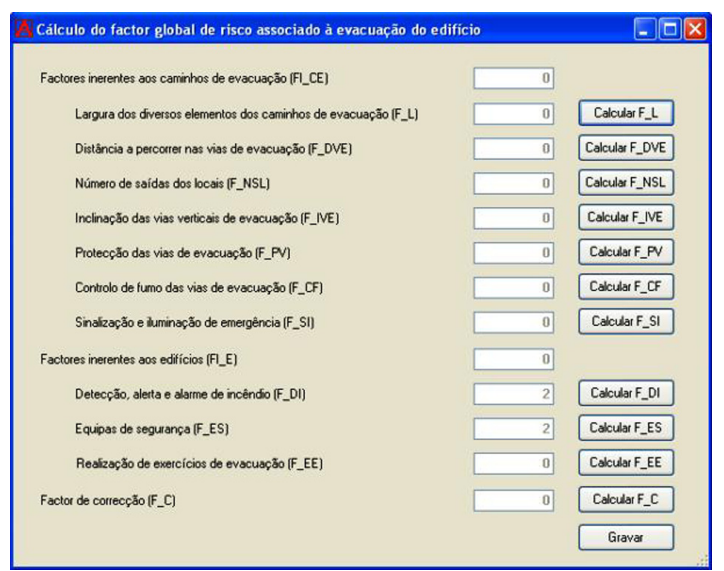

Fig. 16 - Valor calculado para FES e FDI no FGEI (Fonte: software ARICA).

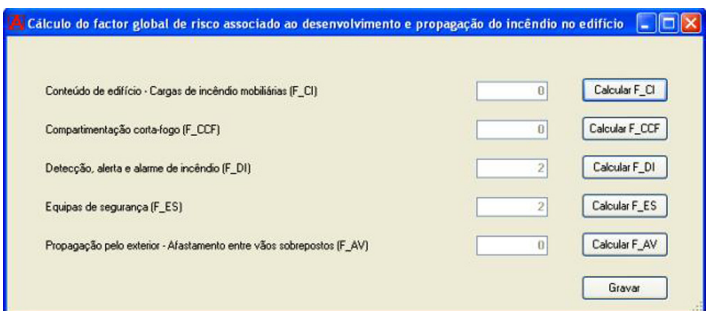

Fig. 17 - Valor alterado automaticamente a FES e FDI no FGDPI (Fonte: software ARICA).

\begin{tabular}{|c|c|c|}
\hline \multicolumn{2}{|c|}{ Cálculo do factor global de eficácia associado ao combate ao incéndio } & \multirow[t]{2}{*}{$-[E$} \\
\hline Factores exteilioes de combate so incerndio no edficio (FE_CI) & 0 & \\
\hline Acessibilidade ao edfficio (F_AE) & 0 & Calcular F_AE \\
\hline Hidrantes extertiones (F_HE] & 0 & Calculat F_HE \\
\hline Fiabridiade da rede de alimentação de água $\left(F_{-} F\right)$ & 0 & Calcular $F_{-} F$ \\
\hline Factores interiores de combate ao incêndio no edficicio $[F[C]$ ] & 0 & \\
\hline Extintores (F_EXT) & 0 & Calcular F_EXT \\
\hline Redes de incêndio amadas [F_Rila] & 0 & Calcular F_RlA \\
\hline Colunas secas ou huimidas $\left[F_{-} C S / H\right]$ & 0 & Calcular F_CS/H \\
\hline Sistemas sutomsticos de exting $z_{0}$ (F_SAE] & 0 & Calcular F_SAE \\
\hline Fiabidade da rede de alimentaço de dgua (F_F] & 0 & \\
\hline \multirow[t]{2}{*}{ Equipas de seguranca (F_ES) } & 2 & Calcular F_ES \\
\hline & & Gravar \\
\hline
\end{tabular}

Fig. 18 - Valor atribuido a FES no FGCT (Fonte: software ARICA).

\section{Cálculo de um factor global}

Os factores globais são determinados automaticamente após todos os factores parciais que o constituem estejam definidos. No caso exemplificado (fig. 19), os diversos factores parciais do factor global, $\mathrm{FGCl}$, apresentam-se totalmente calculados.

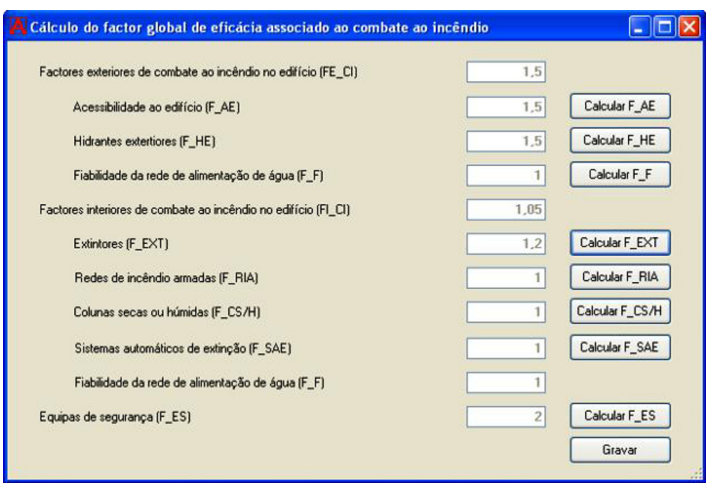

Fig. 19 - Valor atribuído a FES no FGCI (Fonte: software ARICA).

Na Figura 20 verifica-se o valor obtido para o factor global de risco associado ao combate ao incêndio, no caso 1,52 , que somente é calculado e vísivel após o cálculo de todos os factores parciais que constituem esse factor global(fig. 19).

\section{Relatório e sua impressão}

Após todos os campos relativos à identificação do edifício e todos os valores de todos os factores parciais e globais obtidos o relatório gera-se automaticamente. 
O relatório pode possuir extensão .rtf (Ritch Text Format) ou .xls (Folha de Cálculo Excel), consoante a opção do utilizador e pode ser obtido através do comando “Exportar" (fig. 21).

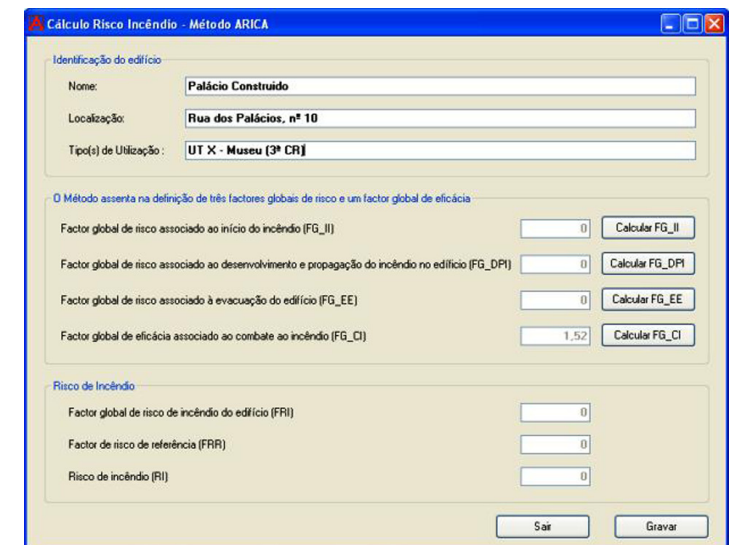

Fig. 20 - Apresentação, na janela resumo, do valor obtido para um factor global (Fonte: software ARICA).

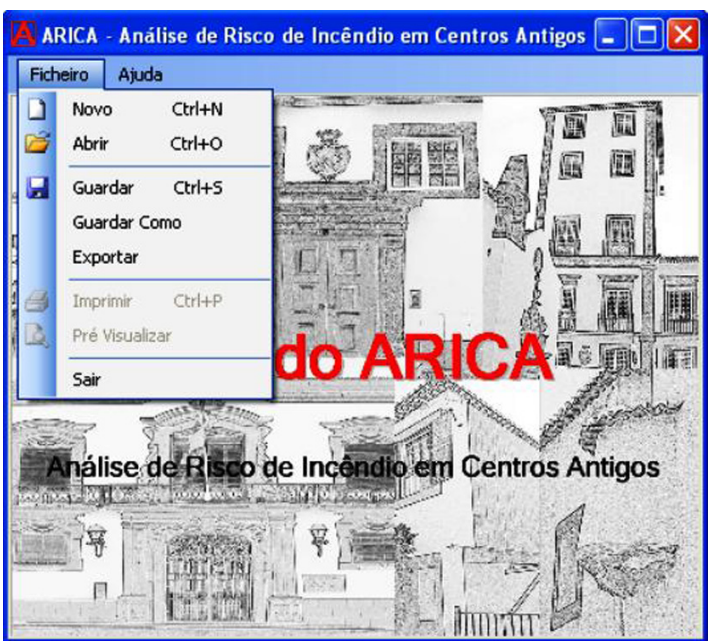

Fig. 21 - Comando "Exportar" para gerar relatório do ARICA (Fonte: software ARICA).

\section{Conclusão}

O desenvolvimento dum programa de computador referente ao método ARICA, versão Beta, permite de uma forma mais cómoda e rápida o cálculo do risco de incêndio num edifício. Sendo a versão apresentada no artigo "Beta", deverá a mesma ser objecto de mais testes para a detecção de qualquer erro ainda existente.

Este programa de computador permite ainda o teste de inúmeros casos duma forma sistemática e inteligível, o que não permitia a aplicação do método manualmente, traduzindo-se isto numa economia de tempo e numa maior segurança nos resultados obtidos.

Este programa, como referido ao permitir a impressão dum relatório em ficheiro editável .rtf ou . xls, com os valores de todos os factores parciais, factores globais, identificação do edifício e do valor obtido para o risco de incêndio, traduz-se numa mais-valia na análise dos diferentes casos de estudo.

Uma nova versão deste programa encontra-se em elaboração, com os erros de versões anteriores corrigidos, um melhor aspecto gráfico dos menus e uma maior facilidade de aplicação pelo utilizador.

\section{Referências bibliográficas:}

Fernandes, Ana Margarida S. (2006) - "Segurança ao Incêndio em Centros Urbanos Antigos". Dissertação para Mestrado, Departamento de Engenharia Civil da Universidade de Coimbra. Coimbra, Portugal;

Figuelra, Rui A. F. (2008) - "Avaliação do Risco de Incêndio em Centros Urbanos Antigos”. Dissertação para Mestrado, Departamento de Engenharia Civil da Universidade de Coimbra. Coimbra, Portugal. 